\title{
Modification of the Beam as Solution of Irregular Building due to Seismic Load
}

\author{
Ririt Aprilin Sumarsono ${ }^{1 *}$ and Muhammad Aji Fajari ${ }^{1}$ \\ ${ }^{1}$ Universitas Negeri Jakarta, Civil Engineering Department, 13220 Rawamangun, Indonesia
}

\begin{abstract}
In recent years, deterioration due to seismic activity has been widely emerged in earthquake prone areas all over the world. Most structures without seismic consideration fail massively due to many reasons, for instance: irregularity problem, low quality of material, reinforcement insufficiency, and so forth. This paper will highlight the analysis of the irregular building simulation using dilatation by modifying the beam in some re-entrant corners and create it as separation inside the building. Variation of placement for the modified beam is examined to the applied high rise building; specifically console beam and Gerber beam. Convincingly, console beam is identified to provide better result for overcoming irregularity problem for both horizontal and vertical irregularity whereas period of structure can be shortened by attempting it as well as other behaviour parameters. Shear wall appearance will certainly increase the performance of the structure, but it will be necessarily needed for Gerber beam rather than console beam. Eminency of Gerber beam is greater probability for reducing the mass of structure since the dimension can be adjusted to be smaller than the main beam; otherwise further consideration of cantilever and intermediate span of the Gerber beam needs extra efforts.
\end{abstract}

Keywords: Configuration irregularity, console beam, Gerber beam, ground motion, behaviour of structure

\section{General}

The needs of better building view has increase the demand of unique and artsy building plan recently. Architectural configuration requirements proposed by Le Corbusier defines that the tenets of modern architecture are open first floor, free plan, free facade, strip windows, and roof terraces - roof gardens [1]. Furthermore, advanced technology in materials including composite can already fulfil the criteria of glamorous but safe in the same time so that the authenticity of the building can even be detected from its look.

However, design criteria of the building must meet the demand perfectly in order to provide safety requirement as advisable as the users comfort while being inside the building. Understanding of external loads which will be subjected to the building, plan building criteria, soil condition, and so forth must be some efforts to be worked on during design

${ }^{*}$ Corresponding author: ririt-aprilin@unj.ac.id 
process. Efficiency of the member structure should also be complied in addition to reduce the cost. Grounding on the previous facts, seismic design for structures has been famous to be inserted for many design structures including building and bridges.

It cannot be denied that most of the artsy building employs complicated plan which is detected to have irregularity either in vertical or horizontal direction. Referring to the seismic code, those irregularities will lead different seismic design requirements. The experiences from past earthquake have shown that the irregularity either in plan or in elevation is of crucial importance on earthquake performance of structures [2].

\subsection{Irregularity criteria}

Regular configuration of a building in plan and elevation is strongly recommended for the earthquake design. Barely, most of high rise building today meets the criteria of irregularity due to many structural and architectural aspects. Symmetric building plan is also well suggested in order to satisfy flexibility criteria. Furthermore, as the asymmetric and irregular buildings are vulnerable to ground excitations, the issue of mitigating the torsional effects has also been raised [3].

Horizontally irregular plan criteria based on [4] including torsion, extreme torsion, reentrant corner, diaphragm discontinuity, out-of-plane offset and non-parallel system irregularity. Next, the category of vertical irregularity are soft story, mass, set-back, in-plane discontinuity in lateral-force-resisting vertical elements, and weak story. In earthquake resistant design, the soft story and the weak story irregularities are reciprocal to a significant difference between the stiffness and the resistance of one of the floors of a building and the rest of them [1].

Specifically, this paper will focus on re-entrant corner and soft story irregularity as the research object is claimed so. Re-entrant corner happens at most in complex building plan (see Fig. 2) where its category determined if the re-entrant reaches $15 \%$ at the desired direction as shown in Fig.1. Re-entrant corner is the location where the stress is highly concentrated which direct to collapse mechanism. Meanwhile soft story is defined as a story of a building significantly less stiff than adjacent stories (that is, the lateral stiffness is $70 \%$ or less than that in the story above, or less than $80 \%$ of the average stiffness of the three stories above) [5].
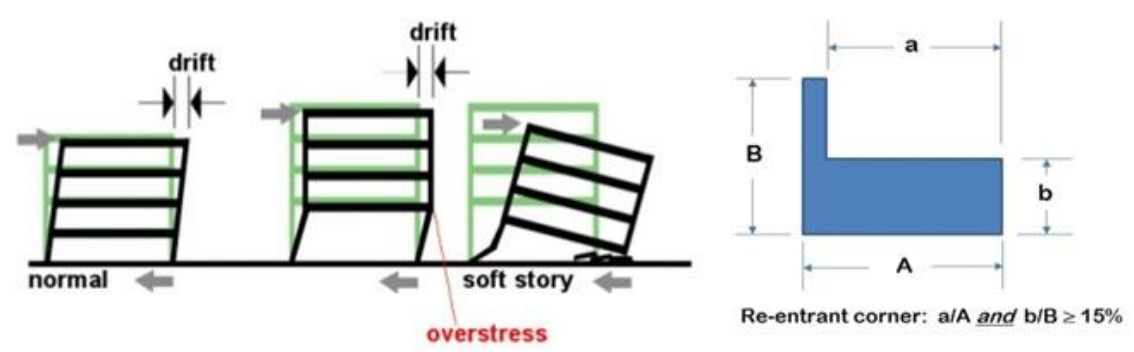

Fig. 1. Soft story and re-entrant irregularity

During seismic events, irregular building will behave more excessive than regular building. In order to control its behaviour, seismic resistant system is considered to be installed. Shear wall is one of the most favourites systems among some alternatives. Reinforced concrete wall suffers from tension cracks developing in the tension areas while there is compressive crushing occurring in the localized compression zones at large cyclic excursions [6]. On the other hand, dilatation can be such solution to be applied. 


\subsection{Dilatation}

Facing the problems of complicated building plan which has complex shapes, it is exceptionally suggested to break the building into several parts of simple regular shapes. Those with complex shapes undergo complex unacceptable structural seismic behaviour [7]. Refer to Fig. 2, simple shapes can be concluded as symmetric plan which centre mass and stiffness is hoped in the same location or at least has small eccentricity.

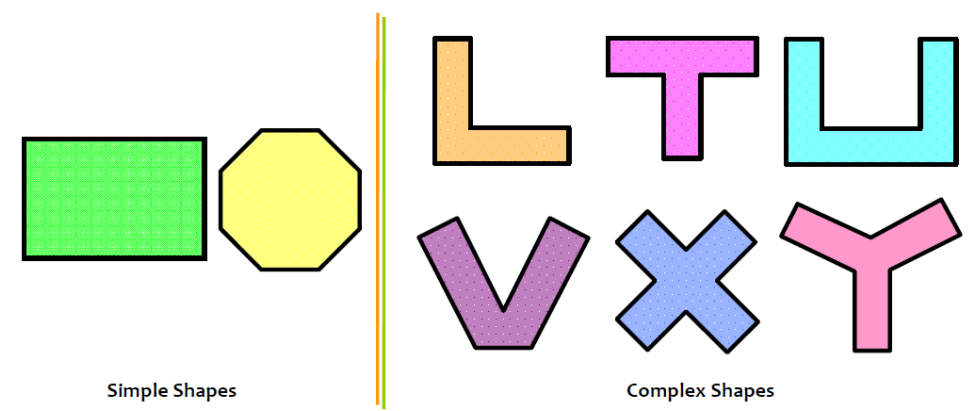

Fig. 2. Simple and complex building configuration

Several solutions are proposed to disjoint the complex shape building into simple such as double column, console beam, cantilever beam, and Gerber beam. Double column system produces faultless disconnection in the re-entrant location. Whilst, the choice of modifying the beam as dilatation by using console, cantilever, and Gerber will not visibly separate the re-entrant corner. They will just improve the behaviour of the irregular building toward regular one.

Gerber beam system consists of simply supported beams with cantilever overhangs in alternate spans. The overhanging beams are linked by intermediate beams supported on the overhang tips. The original idea of the Gerber system is to introduce internal hinges between the overhang tips and the intermediate beams [8]. There are two benefits of harnessing Gerber system which are forming the beam into statically determinate beams and optimizing the negative moment of cantilever span at the support location (column) nearly equal to maximum positive span at the mid-span. Furthermore it is possible to have different dimension of cantilever span and intermediate beam depends on the connection details which will be used

Utilization of console (corbel) beam somehow simplifies the joint re-entrant, but proper column modification must be well considered. The term "corbel" is generally restricted to cantilevers having shear span-depth ratios less than unity [9]. Arranging either cantilever beams (first type console) or offsetting the side columns to the periphery of the building and supporting them on corbels (second type console) is the technique of console beam [10]. Typical failures happen in console beam are yielding of tension reinforcement, crushing or splitting of the compression strut, and localized bearing or shearing failure under the loading plate [9].

For simplification, this paper will use the continuous dimension of the beam particularly for Gerber. The cantilever part of the Gerber was set to be $0.8 \mathrm{~m}$ and the intermediate beam is the remaining span from the total beam length. Since finite element analysis for the Gerber stresses does not take into focus, the modification of restraint is applied into simple end support. The same thing applies for the console, where one end was set as roller which rotation and translation move in $X$ and $Y$ directions are allowed. 


\section{Parametric study}

This paper will utilize symmetric $U$ shaped building equipped with shear wall in several parts of the building. Linear dynamic analysis will be performed by using structural software ETABS v.13 by inputting response spectra data based on the site class of the building site.

\subsection{Building details}

This residential building is named Heliconia Apartment Tower which is part of Bassura City building complex. The installation of shear wall in several sections is symmetrically arranged. Focus on Fig. 3, plan irregularity of this building due to re-entrant corner are 48\% in $X$ direction and $63 \%$ in $Y$ direction, moreover soft story is noticed due to untypical floor height in ground floor.
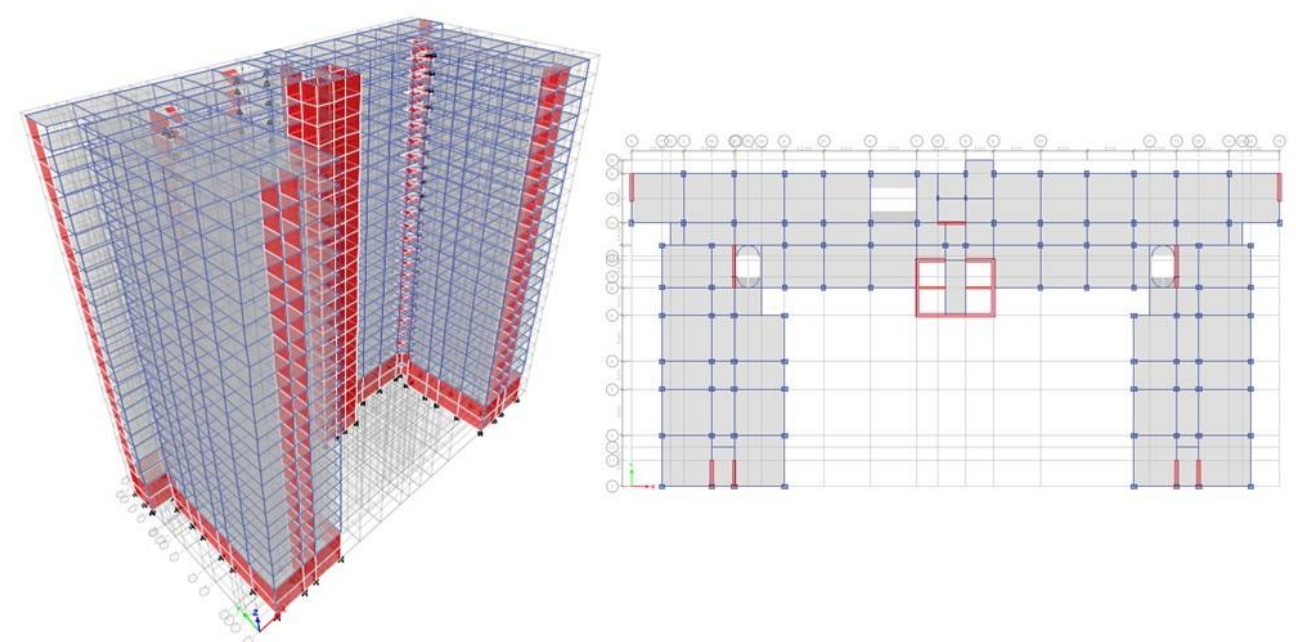

Fig. 3. Building plan

As for research needs, some model alternatives are developed starting from eliminating the shear wall and replace it with the columns for Non-Shear Wall (NSW) model. Expansion of model is parallel to the aim of dilating the building through console beam (CB) and Gerber beam (GB). Each CB and GB will have 4 model variations (M1 through M4) with or without shear wall as seen in Fig. 4where red lines inform the dilatation location through beam modification.
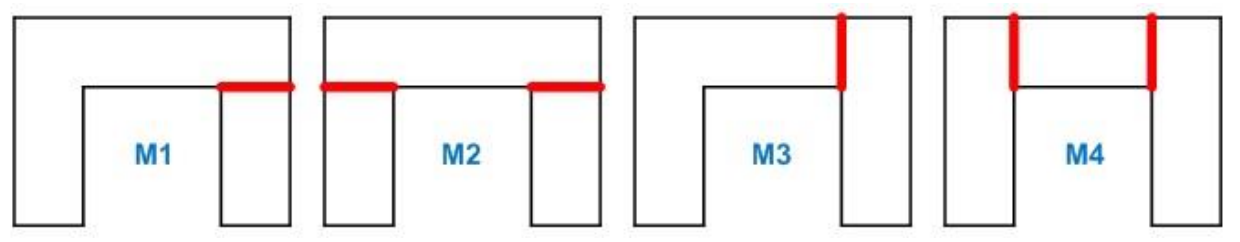

Fig. 4. Model variation for dilatation

Determination of dilatation location was restricted to straight line of the beam from the existing building. As M1 and M2 is dilated in $X$ direction, in contrary M3 and M4 is in $Y$ direction. 


\subsection{Structural data}

Details of structural data and properties can be referred in Table 1 where several floors are changing in dimension and/or material properties. Soft story happened in LG (lower ground floor) occurs due to extreme different height among upper and bottom floor.

Table 1. Properties and dimension of structural member

\begin{tabular}{|c|c|c|c|c|}
\hline No. & $\begin{array}{c}\text { Structural } \\
\text { member }\end{array}$ & Floor & $\begin{array}{c}\text { Dimension } \\
(\mathrm{mm})\end{array}$ & $\begin{array}{c}\text { Material properties } \\
(\mathrm{MPa})\end{array}$ \\
\hline \multirow{3}{*}{1} & \multirow{3}{*}{ Column } & $\mathrm{B} 1-\mathrm{GF}$ & $\mathrm{K} 1 \mathrm{H}-1 \mathrm{H}--450 \times 1000$ & 44.13 \\
\cline { 3 - 5 } & & $1 \mathrm{~F}-15 \mathrm{~F}$ & $\mathrm{~K} 1 \mathrm{H}-3 \mathrm{H}--450 \times 800$ & 39.23 \\
\cline { 3 - 5 } & & $16 \mathrm{~F}-\mathrm{RF}$ & $\mathrm{K} 1 \mathrm{H}-5 \mathrm{H}--450 \times 600$ & 34.23 \\
\hline \multirow{3}{*}{2} & \multirow{3}{*}{ Beam } & $\mathrm{B} 1-\mathrm{GF}$ & $\mathrm{G} 34 \mathrm{~A}-1--300 \times 450$ & 34.23 \\
\cline { 3 - 5 } & & $1 \mathrm{~F}-15 \mathrm{~F}$ & $\mathrm{G} 34 \mathrm{~A}-1--300 \times 450$ & 34.23 \\
\cline { 3 - 5 } & & $16 \mathrm{~F}-\mathrm{RF}$ & $\mathrm{G} 34 \mathrm{~A}-2--300 \times 450$ & 29.42 \\
\hline \multirow{2}{*}{3} & \multirow{2}{*}{ Slab } & & 130 & 34.23 \\
& & & 200 & 34.23 \\
\hline \multirow{3}{*}{4} & \multirow{3}{*}{ Wall } & $\mathrm{B} 1-\mathrm{GF}$ & $\mathrm{W} 1 \mathrm{H}-1-350$ & 44.13 \\
\cline { 3 - 5 } & & $\mathrm{F}-15 \mathrm{~F}$ & $\mathrm{~W} 1 \mathrm{H}-2-350$ & 39.23 \\
\cline { 3 - 5 } & & $16 \mathrm{~F}-\mathrm{RF}$ & $\mathrm{W} 1 \mathrm{H}-3-350$ & 34.23 \\
\hline
\end{tabular}

\subsection{Ground motion}

A plot of maximum amplitudes (acceleration, velocity, or displacement) of a single-degreeof-freedom oscillator (SDOF), as the natural period of the SDOF is varied across as spectrum of engineering interest (typically, for natural periods from 0.03 to 3.0 or more seconds, or frequencies of 0.3 to 30 or more hertz), is defined as response spectrum [5]. This spectra data will be included in the load combinations which is required by [4] to be as follow:

\section{$1.4 D L$}

$1.2 D L+1.6 L L$

$1.2 D L+1.0 L L \pm 0.3\left(\rho Q_{E X}+0.2 S_{D S} D L\right) \pm 1.0\left(\rho Q_{E Y}+0.2 S_{D S} D L\right)$

$1.2 D L+1.0 L L \pm 1.0\left(\rho Q_{E X}+0.2 S_{D S} D L\right) \pm 0.3\left(\rho \mathrm{Q}_{E Y}+0.2 S_{D S} D L\right)$

$0.9 D L \pm 0.3\left(\rho Q_{E X}-0.2 S_{D S} D L\right) \pm 1.0\left(\rho Q_{E Y}-0.2 S_{D S} D L\right)$

$0.9 D L \pm 1.0\left(\rho Q_{E X}-0.2 S_{D S} D L\right) \pm 0.3\left(\rho Q_{E Y}-0.2 S_{D S} D L\right)$

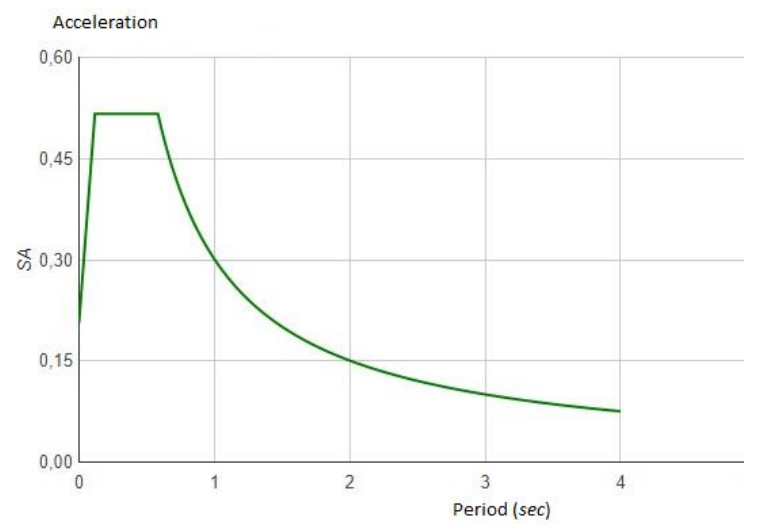

Fig. 5. Response spectra 
It was observed that base shear developed based on seismic coefficient method and that by response spectrum method were almost matching or were very close for $5 \%$ damping in the system [11]. Once the site class is determined, the value of $S_{D S}$ and $S_{D 1} 0.516 \mathrm{~g}$ and $0.301 \mathrm{~g}$ can be traced to reproduce the response spectra curve as shown in Fig. 5. The contribution of spectra will be equal to seismic force applied in $X$ and $Y$ direction of the building. Noting that not both directions use $100 \%$ seismic force, another direction will employ $30 \%$ only.

\section{Results and discussion}

In this chapter discussions regarding structural response and structural capacity will be cordially talked in relationship with several dilatation models. Whether shear wall participation in upgrading the behaviour of structure will be significant, we need to further see the analysis results.

\subsection{Structural response}

Modelization of all variations (M1 to M4) results constant mass for each SW and NSW model. It is noted that shear wall adds about $10 \%$ from the NSW building system. Later, its contribution can be clearly seen in the base shear and reduction of displacement. Either console or Gerber beam does not create significant augment to the mass of structure for both SW and NSW model as served in Fig. 6.

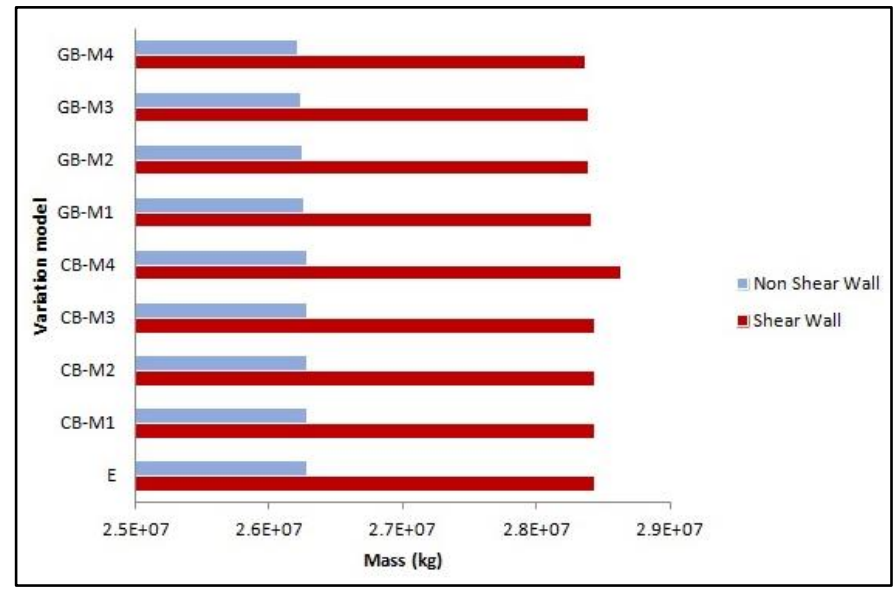

Fig. 6. Mass of structure

\subsubsection{Frequency of structure}

The reciprocal of natural period $\left(T_{n}\right)$ of a building is called natural frequency $\left(f_{n}\right)$; its unit is Hertz $(\mathrm{Hz})$. The building offers least resistance when shaken at its natural frequency [7]. Observing Fig. 7, the highest frequency of SW model is occurred for CB-M4 model; otherwise NSW model is noticed for CB-M1 model. Generally, all the models result almost the same value as the existing model. All GB models shows smaller frequency than CB models which means higher period also even though just a slight difference. Shear wall participates better in declining the period of structure, however CB model performs better than GB. 


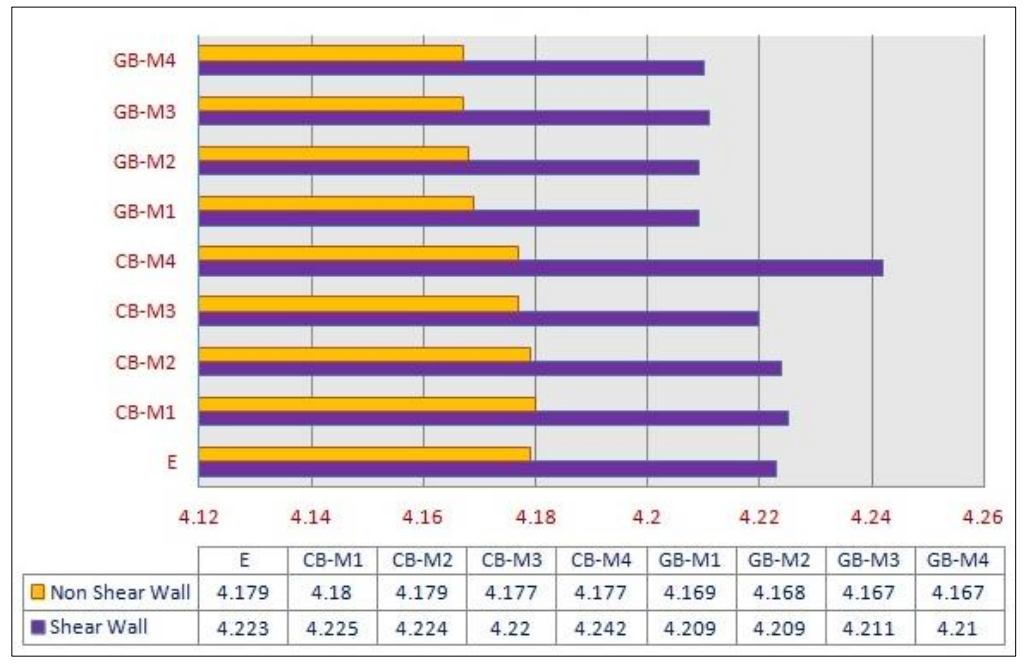

Fig. 7. Frequency of SW and NSW model structure

Knowing that the location of dilatation is vary set in $X$ and $Y$ direction, it seems to be constant result of structural period. No clear difference of improvements whether it is placed at $X$ or $Y$ direction based on period and frequency parameters.

\subsubsection{Base shear}

Representing base shear values based on Table 2, we can notice the same pattern as frequency and period parameter analysis which is not directed into great difference for both $\mathrm{CB}$ and GB models. Base shear as the seismic codes considering importance factor of 1 for residential is the percentage of modal mass responding to the earthquake in each mode [11]. Mode 1 of the structural system is the main concern to be analysed as the base shear values spread in Table 2.

Table 2. Base shear

\begin{tabular}{|c|c|c|c|c|c|}
\hline SW model & $\begin{array}{c}V_{\boldsymbol{X}} \\
(\mathbf{k N})\end{array}$ & $\begin{array}{c}\boldsymbol{V}_{\boldsymbol{Y}} \\
(\mathbf{k N})\end{array}$ & NSW model & $\begin{array}{c}\boldsymbol{V}_{\boldsymbol{X}} \\
(\mathbf{k N})\end{array}$ & $\begin{array}{c}\boldsymbol{V}_{\boldsymbol{Y}} \\
(\mathbf{k N})\end{array}$ \\
\hline E-SW & 47309.42 & 4085.26 & E-NSW & 52265.13 & 4570.15 \\
\hline CB-SW-M1 & 47230.13 & 4079.60 & CB-NSW-M1 & 52251.43 & 4571.60 \\
\hline CB-SW-M2 & 47176.06 & 4054.33 & CB-NSW-M2 & 52229.86 & 4458.64 \\
\hline CB-SW-M3 & 47246.54 & 4089.77 & CB-NSW-M3 & 52214.93 & 4588.85 \\
\hline CB-SW-M4 & 45658.43 & 4058.13 & CB-NSW-M4 & 52195.10 & 4581.76 \\
\hline GB-SW-M1 & 47232.85 & 4090.58 & GB-NSW-M1 & 52193.43 & 47176.06 \\
\hline GB-SW-M2 & 47429.31 & 4055.87 & GB-NSW-M2 & 52262.91 & 4521.49 \\
\hline GB-SW-M3 & 47051.62 & 4062.98 & GB-NSW-M3 & 52034.93 & 4623.32 \\
\hline GB-SW-M4 & 46990.63 & 4089.27 & GB-NSW-M4 & 51975.15 & 4610.22 \\
\hline
\end{tabular}

Understanding the strong axis of building is in $\mathrm{X}$ direction, base shear value for all variations have greater value in this direction confidently. Nonetheless, base shear Y deliver about one tenth of base shear Y, thus displacement and drift can be predicted to hold greater value as well. Comparing SW and NSW base shear results; about $10 \%$ addition is contributed to NSW value to SW. This condition is leading the same fact of almost $10 \%$ mass as elaborated previously. The higher mass, the lower base shear resulted. 
Detail speaking about the location of the dilatation, none of the applied direction heads to specific conclusion of better behaviour. It is merely the same behaviour as the existing building without any distinct difference.

\subsubsection{Displacement and Drift}

Lateral drift is evaluated on a story by story basis. Story drift is computed as the difference in lateral deflection at the top of a story and that at the bottom of the story, as predicted by lateral analysis [5]. Fig. 8 explains the plot of displacement and drift curve for SW system where both $\mathrm{CB}$ and GB models generate a slight lower displacement than that existing (E) model. CB-SW and CB-NSW model are established to perform better than GB in terms of top displacement value. M2 and M4 are the best dilatation location which yield the assumption of placing more beams will prohibit higher displacement for both $X$ and $Y$ direction.

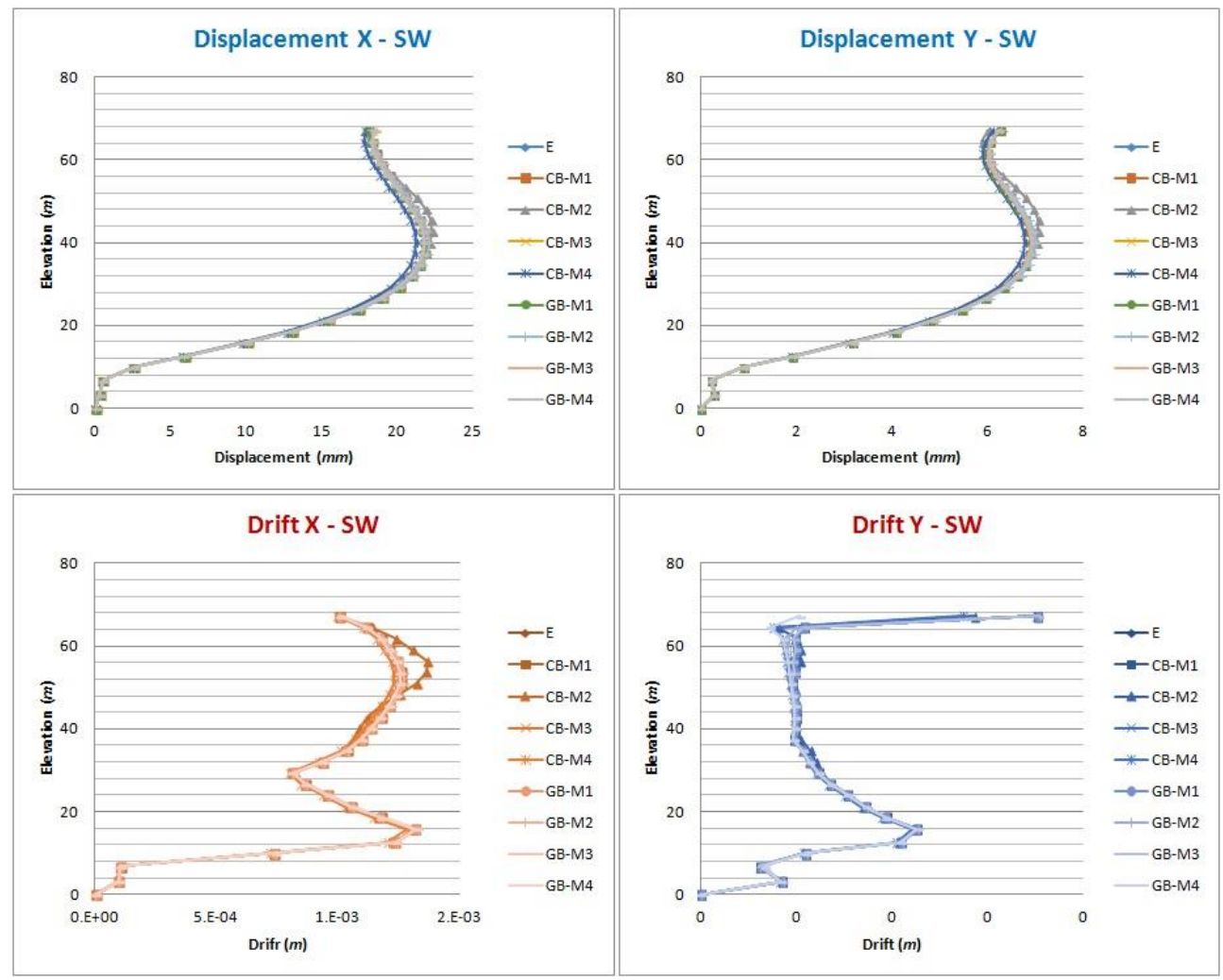

Fig. 8. Displacement and drift $(X$ and $Y)$ for SW model

On the other hand, excessive drift $X$ takes place in the soft story floor, but in top floor for drift $Y$. Tendency of having smaller drift for M1 and M2 happens only for $X$ direction, in contrary M3 and M4 are better drift $Y$. As noticed that shear wall covers more in $Y$ direction, then placing more beams will be stiffer in strong axis rather than weak axis of building.

Almost the same explanation for NSW results in drift and displacement result where displacement and drift value are greater than SW due to the absence of contribution from the shear wall. About 6 percent increment for all displacement values from SW model is quantified. Referring to Fig. 9, drift Y plot is untidy and shows better drift than existing. 


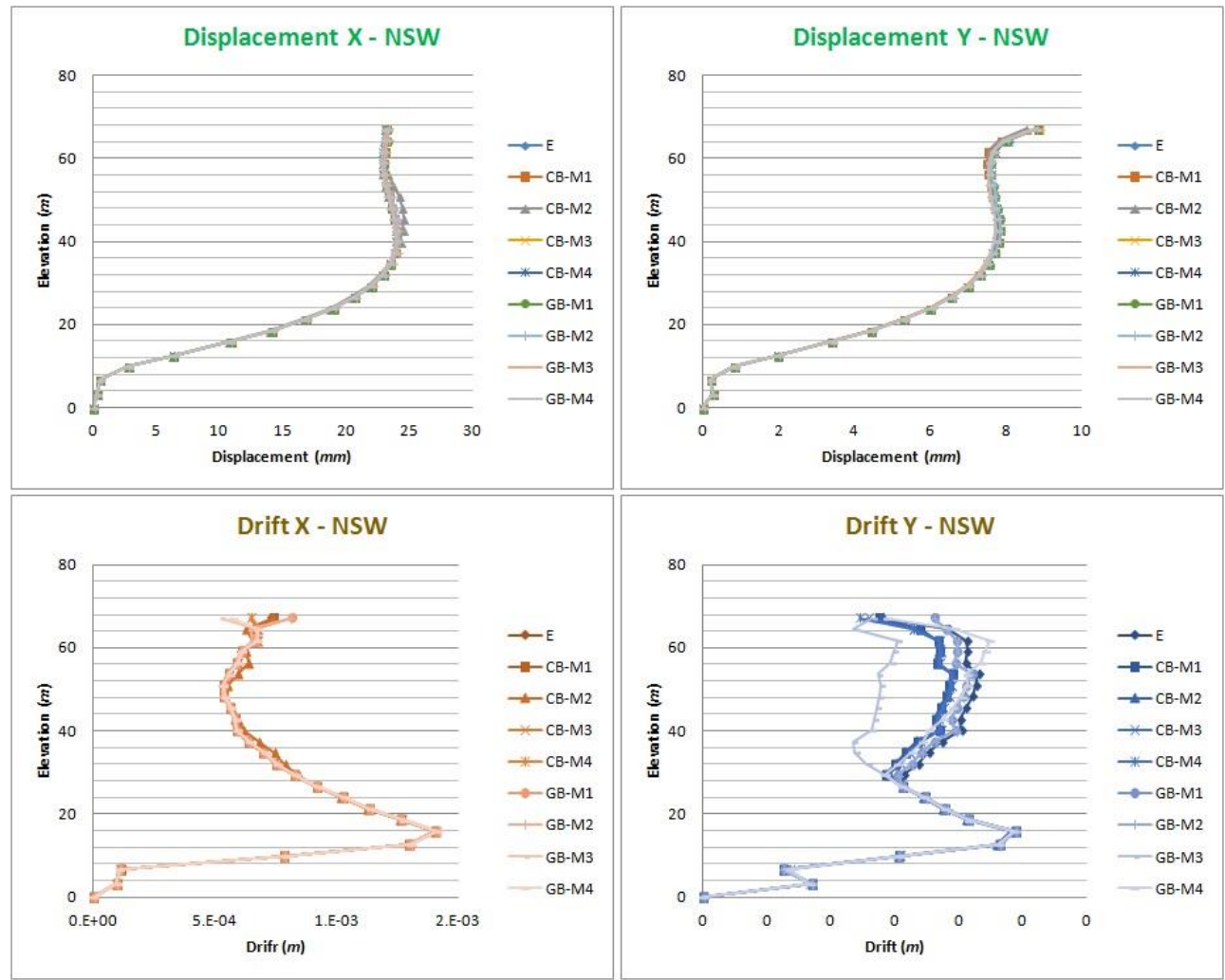

Fig. 9. Displacement and $\operatorname{drift}(X$ and $Y)$ for NSW model

\subsection{Capacity of axial member}

Column in majority is strong under the axial compression load. In fact, in modern seismic design codes, the concrete columns under seismic loading were required to be able to sustain relatively large inelastic deformations without any significant loss of load-carrying capacity [12]. Based on Fig. 10, the resulted axial load which needs to be resisted by K1H-1H column is safely encountered. It can be seen that the column capacity is extremely high even without shear wall it can still hold the excessive lateral seismic load.
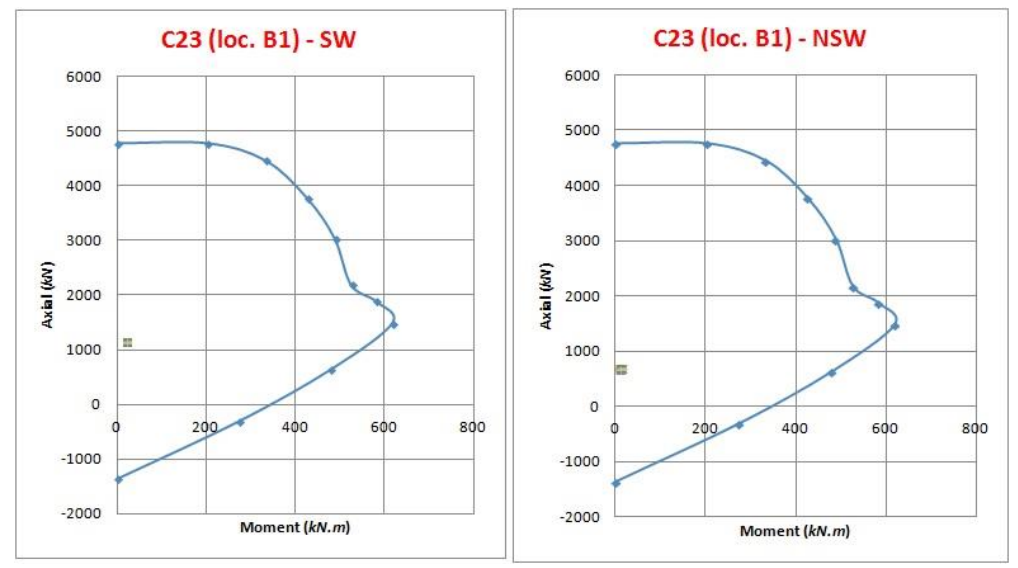

Fig. 10. Column capacity of K1H-1H under CB and GB model 


\subsection{Capacity of flexural member}

Two beams are taken into consideration to be observed its shear and flexure capacity. One dilatation model location of M2 is also selected to be the focus of discussion as provided in Table 3. Strong evidence that beams suffer more than the columns is distinct; especially when the shear wall disappears. Shear capacity is decreased by more than half for B88, furthermore moment capacity is extremely downgrade. Installation of dilatation also proves for no big impact compare to existing building.

Table 3. Flexure and shear capacity of B 88 and B90

\begin{tabular}{|c|c|c|c|c|c|}
\hline \multirow{2}{*}{ Model } & \multirow{2}{*}{ Floor } & \multicolumn{2}{|c|}{ B88 } & \multicolumn{2}{c|}{ B90 } \\
\cline { 3 - 6 } & & $\begin{array}{c}\text { Shear } \\
(\boldsymbol{k} \boldsymbol{N})\end{array}$ & $\begin{array}{c}\text { Flexure } \\
(\boldsymbol{k} \boldsymbol{N} . \boldsymbol{m})\end{array}$ & $\begin{array}{c}\text { Shear } \\
(\boldsymbol{k} \boldsymbol{N})\end{array}$ & $\begin{array}{c}\text { Flexure } \\
(\boldsymbol{k} \boldsymbol{N} . \boldsymbol{m})\end{array}$ \\
\hline E-SW & RF & -268.23 & 298.90 & -71.54 & 71.82 \\
\hline & $15 \mathrm{~F}$ & -242.84 & 286.60 & -69.11 & 84.40 \\
\hline & B1 & -16.75 & 28.37 & -4.67 & 9.16 \\
\hline CB-SW-M2 & RF & -268.08 & 299.78 & -71.41 & 72.55 \\
\hline & $15 \mathrm{~F}$ & -242.86 & 286.62 & -33.49 & -29.12 \\
\hline & B1 & -16.76 & 28.40 & 15.76 & 8.90 \\
\hline GB-SW-M2 & RF & -268.53 & 299.52 & -71.80 & 72.33 \\
\hline & $15 \mathrm{~F}$ & -242.84 & 286.63 & -33.50 & -29.13 \\
\hline & B1 & -16.76 & 28.40 & 15.76 & 8.90 \\
\hline & RF & -95.75 & 40.47 & 10.51 & 26.24 \\
\hline & $15 \mathrm{~F}$ & -91.18 & 38.76 & 4.84 & 29.04 \\
\hline E-NSW & B1 & -29.32 & 20.55 & 5.63 & 21.86 \\
\hline & RF & -95.82 & 40.49 & 10.51 & 26.47 \\
\hline & $15 F$ & -91.20 & 38.79 & 4.86 & 29.06 \\
\hline & B1 & -29.32 & 20.55 & 5.62 & 21.87 \\
\hline GB-NSW-M2 & RF & -95.79 & 40.46 & 10.43 & 26.43 \\
\hline & $15 \mathrm{~F}$ & -91.20 & 38.78 & 4.86 & 29.05 \\
\hline & B1 & -29.33 & 20.55 & 5.63 & 21.87 \\
\hline
\end{tabular}

\section{Conclusions}

Wholly, dilatation by modifying the beam using console and Gerber beam serves satisfying results compare to existing building. The followings are compact summary regarding all the discussions above:

a. Console beam is most preferable to be applied as the dilatation due to some better behaviour parameters compare to Gerber. However, Gerber can also be applied as long as the number of modified beams and its location is suitable and accurate. Both systems perform even better once the shear wall is attached.

b. Strong axis behaviour of the building will not be influenced by application of the beam dilatation, otherwise weak axis must be highly considered on how many beams dilatation to be employed. Greater shear wall contribution in weak axis will balance the dilatation.

c. Further experiment of cantilever length and intermediate span length should be worth to be done in order to find the most application which directs to better behaviour of structure.

\section{References}

1. L. T. Guevara-perez, pp. 518-519, (2009).

2. K. Güler, M. G. Güler, B. Taskin, and M. Altan, 14th WCEE, no. 2004, (2008).

3. G. Georgoussis, A. Tsompanos, and T. Makarios, Procedia Eng., 125, pp. 959-966, (2015). 
4. B. S. Nasional, Tata cara perencanaan ketahanan gempa untuk struktur bangunan gedung dan non gedung. (2012).

5. W.-F. Chen and C. Scawthorn, Earthquake Engineering Handbook, (2003).

6. X. Zhang, Y. Qin, and Z. Chen, JCSR, 116, pp. 218-232, (2016).

7. C. V. R. Murthy, G. Rupen, A. R. Vijayanarayanan, and V. V. Mehta, Some concepts in earthquake behavior of buildings. (2012).

8. F. Nowzartash, N. Markiz, and M. E. Mohareb, 53th ISSC, (2012).

9. S. Hwang, W. Lu, and H. Lee, ACI Struct. J., pp. 543-552, (2000).

10. K. Guler and M. Altan, 13th World Conference on Earthquake Engineering, (2004).

11. I. Chowdhury and S. P. Dasgupta, Dynamics of Structure and Foundation - A Unified Approach, (2009).

12. K. Choi, G. T. Truong, and J. Kim, Eng. Struct., 126, pp. 490-504, (2016). 